Volume 8, No.6, November -December 2019

International Journal of Science and Applied Information Technology

Available Online at http://www.warse.org/ijsait/static/pdf/file/ijsait08862019.pdf

https://doi.org/10.30534/ijsait/2019/088620198

\title{
General Balanced Magic Squares
}

\author{
Saleem Al-ashhab ${ }^{1}$, Laith Abualigah ${ }^{2}$ \\ ${ }^{1}$ Department of Mathematics, AABU, Mafraq, Jordan \\ ${ }^{2}$ Faculty of Computer Science and Informatics, Computer Science Department, \\ Amman Arab University, Amman, Jordan
}

\begin{abstract}
In this paper we consider the problem of counting magic squares 6 by 6 . We introduce and study special types of magic squares of order six. We present the property preserving transformations. We list the enumerations of the squares, which processes special features.
\end{abstract}

Key words : Magic squares; Four corner propery; Balanced magic squares

\section{INTRODUCTION}

In this paper we consider the old famous problem of magic squares. A semi magic square is a square matrix, where the sum of all entries in each column or row yields the same number. Some authors call it magic square. This number is called the magic constant. We call a semi magic square a magic square if both main diagonals sum up to the magic constant. A natural magic square of order $n$ is a matrix of size $n \times n$ such that its entries consist of all integers from one to $n^{2}$. The magic constant is in this case

$0.5 n\left(n^{2}+1\right)$

a natural magic square of order three

\begin{tabular}{|l|l|l|}
\hline 8 & 1 & 6 \\
\hline 3 & 5 & 7 \\
\hline 4 & 9 & 2 \\
\hline
\end{tabular}

The combinations, which appear in the columns, rows and both diagonals of this square, are the only distinct three element combinations of the numbers from 1 to 9 with sum 15. A symmetric magic square is a natural magic square of order $n$ such that the sum of both elements of each pair of dual (opposite entries) is equal to

$n^{2}+1$

A pandiagonal magic square is a magic square such that the sum of all entries in all broken diagonals equals the magic constant. For example, we note in table 2 that the sum of the entries $34,36,7,44,10,2,42$ is 175 , which is the magic constant. These entries represent the first right broken diagonal.

A natural pandiagonal and symmetric magic square of order seven

\begin{tabular}{|l|l|l|l|l|l|l|}
\hline 39 & 34 & 21 & 35 & 8 & 37 & 1 \\
\hline 9 & 12 & 36 & 24 & 19 & 48 & 27 \\
\hline 30 & 17 & 46 & 7 & 32 & 3 & 40 \\
\hline 6 & 28 & 25 & 22 & 44 & 5 & 45 \\
\hline 18 & 43 & 4 & 33 & 20 & 10 & 47 \\
\hline 31 & 26 & 14 & 38 & 41 & 23 & 2 \\
\hline 42 & 15 & 29 & 16 & 11 & 49 & 13 \\
\hline
\end{tabular}

A pandiagonal and symmetric magic square is called super magic. A complete Magic square is a pandiagonal square with some supplementary qualities. For a complete Magic square of order 4, the sum of the entries: $a_{11}, a_{12}, a_{21}, a_{22}, a_{11}, a_{13}, a_{31}, a_{33} \quad$ and $a_{11}, a_{14}, a_{41}, a_{44}$ is also equal to the magic sum.

It is well known that we have only eight $3 \times 3$ magic squares (with sum in all directions 15). All these squares have the number 5 as a middle entry and all these squares can be formed using the following transformations: rotations with angles $90^{\circ}, 180^{\circ}, 270^{\circ}$ and reflections about the middle column, middle row and both diagonals of the square.

In the seventeenth century F. Bessy was the first person to state that the number of the $4 \times 4$ magic squares is 880 , where he considered a magic square with all its rotations and reflections one square. Hire listed later these squares in tables in the year 1693. Today we can use the computer to check that there are

$880 * 8=7040$

magic squares of order four. At the beginning of the twentieth century these squares were classified theoretically into twelve classes. One of these classes is the class of pandiagonal magic squares consisting of 48 squares. It was proven that they are generated by three basic squares (cf. [1]). In 1973 Schoeppel 
found the number of all natural magic squares of order five. He computed it using an elementary computer. It is $64826306 * 32=2202441792$,

where we multiply by 32 due to the existence of a property preserving transformations. According to [2] there exists 736347893760

natural nested magic squares of order six. According to [3] the number of super magic squares of order five is sixteen and number of super magic squares of order seven is 20190684 . The number of complete magic squares of order four is 48 , and the number of complete magic squares of order eight (cf. [4]) is 368 640. It is well-known that there are pandiagonal magic squares and symmetric squares of order five. It was proven that the pandiagonal magic squares are generated through 144 basic squares. Hence, there are

$144 * 200=28800$

natural pandiagonal squares of order five. But, there are neither pandiagonal magic squares nor symmetric squares of order six. The proof can be found in [3]. The number of natural magic squares of order six is actually unknown up to day. In [5] Trump obtained using empirical methods (Monte Carlo Method) the following interval estimation for this number

\section{$(1.7712$ e $19,1.7796$ e19)}

with a probability of $99 \%$. We give here the number of a subset of such squares. We define here classes of magic squares of order six, which satisfy some of the conditions for both types. In [4] we find an enumeration of some subsets of pandiagonal squares. In the references [5], ..., [10] we find some partial listings for the number of magic squares. In $[11,12]$ there is an enumeration of Franklin squares, which are special magic squares of order 8 by 8 .

\subsection{Four corner magic square}

This concept was introduced by Al-Ashhab for the first time in [5]. Al-Ashhab studied this type there in some simple cases. In [6] Al-Ashhab considered the type called nested four corner magic square with a pandiagonal magic square, where the inside 4 by 4 square was pandiagonal. In [5] we find an enumeration of this class of squares. We can find other enumerations of other classes of squares of this type in the references [7], [8], [9], [10] and [6]. Alashhab and Trump computed in 2015 the number of natural four corner squares. It is 8730627225792 .

1.3 Objectives and Benefits of our Work

The study was focused on squares with centres, which are symmetric, semi symmetric or have positive determinants. In the following subsection we illustrate the previous concepts. In this paper we summarize and present the total enumerations concerning four corner magic squares.

\section{BASIC THEORIES}

\section{[1] 2.1. The types of squares}

A four corner magic square is a magic squares of order six with magic constant $3 \mathrm{~s}$ such that the equations

$$
\begin{aligned}
& a_{33}+a_{34}+a_{43}+a_{44}=2 s, \\
& a_{i i}+a_{i(i+3)}+a_{(i+3) i}+a_{(i+3)(i+3)}=2 s
\end{aligned}
$$

hold for $i=1,2,3$. A four corner magic square of order 6 can be written as

\begin{tabular}{|l|l|l|l|l|l|}
\hline y & f & g & t & M & G \\
\hline z & h & n & j & q & N \\
\hline W & E & e & a & m & D \\
\hline A & k & Q & b & H & R \\
\hline V & p & d & o & Z & T \\
\hline B & F & I & J & L & Y \\
\hline
\end{tabular}

where

$A=2 s-b-t-y, B=b+j+o+t-s-w$,

$\mathrm{D}=\mathrm{d}+\mathrm{g}+\mathrm{n}+\mathrm{y}-\mathrm{a}-\mathrm{p}-\mathrm{q}$,

$\mathrm{E}=3 \mathrm{~s}-\mathrm{a}-\mathrm{e}-\mathrm{m}-\mathrm{w}-\mathrm{D}, \mathrm{F}=3 \mathrm{~s}-\mathrm{f}-\mathrm{h}-\mathrm{k}-\mathrm{p}-\mathrm{E}$,

$\mathrm{G}=2 \mathrm{~s}+\mathrm{e}+\mathrm{w}-(\mathrm{j}+\mathrm{o}+\mathrm{p}+\mathrm{q}+\mathrm{t})$,

$\mathrm{H}=\mathrm{e}+\mathrm{g}+\mathrm{s}+\mathrm{w}+\mathrm{y}-\mathrm{j}-\mathrm{k}-\mathrm{o}-\mathrm{p}-\mathrm{q}$,

$\mathrm{I}=\mathrm{a}+\mathrm{b}+\mathrm{s}-\mathrm{d}-\mathrm{g}-\mathrm{n}, \mathrm{J}=3 \mathrm{~s}-\mathrm{a}-\mathrm{b}-\mathrm{j}-\mathrm{o}-\mathrm{t}$,

$\mathrm{M}=3 \mathrm{~s}-\mathrm{f}-\mathrm{g}-\mathrm{t}-\mathrm{y}-\mathrm{G}, \mathrm{N}=3 \mathrm{~s}-\mathrm{h}-\mathrm{j}-\mathrm{n}-\mathrm{q}-\mathrm{z}$,

$\mathrm{L}=\mathrm{f}+\mathrm{h}+\mathrm{k}+\mathrm{p}-\mathrm{m}-\mathrm{s}, \mathrm{Q}=2 \mathrm{~s}-\mathrm{a}-\mathrm{b}-\mathrm{e}$,

$\mathrm{R}=\mathrm{a}+\mathrm{b}+\mathrm{j}+\mathrm{o}+\mathrm{p}+\mathrm{q}+\mathrm{t}-\mathrm{g}-2 \mathrm{~s}-\mathrm{w}$,

$\mathrm{T}=\mathrm{h}+\mathrm{j}+\mathrm{q}+\mathrm{z}-\mathrm{d}-\mathrm{s}, \mathrm{V}=2 \mathrm{~s}-\mathrm{j}-\mathrm{o}-\mathrm{z}$

$\mathrm{Y}=\mathrm{p}+\mathrm{q}+\mathrm{s}-\mathrm{b}-\mathrm{e}-\mathrm{y}, \mathrm{Z}=2 \mathrm{~s}-\mathrm{p}-\mathrm{q}-\mathrm{h}$.

We see that it has seventeen independent variables, which are represented by the small letters. Further, we see that

$\mathrm{A}+\mathrm{p}+\mathrm{I}+\mathrm{t}+\mathrm{q}+\mathrm{D}=3 \mathrm{~s}$,

$\mathrm{R}+\mathrm{Z}+\mathrm{J}+\mathrm{g}+\mathrm{h}+\mathrm{w}=3 \mathrm{~s}$.

That is two broken diagonals sum up to the magic constant. In this sense we can think about this new type of squares as a partial type of pandiagonal magic squares 6 by 6 .

We call a four corner magic squares such that

$a_{33} a_{44}+a_{34}+a_{43}<0(>0)$

a four corner magic square of order six with negative (positive) center. This means that the 2 by 2 square in the center has negative (positive) determinant.

The number of all different possible values for $a, b$ and $e$ by computing the number of four corner magic squares is 3429 . Hence, there are 3429 possible centers of the natural four corner magic squares. The number of squares with positive center is 232 . Hence, there are 3197 possible centers of the negative four corner magic squares. Among these squares there are 153 (res. 306) centers of the four corner magic squares, which are symmetric (res. semi symmetric). 
A natural four corner magic square

\section{[2] 2.2. Property preserving transformations}

There are seven classical transformations, which take a magic square into another magic square. These transformations also preserve the property "four corner magic". Now, a four corner magic squares can be transformed by executing the following interchanges simultaneously into another one of the same kind:

$$
\begin{aligned}
& \text { interchange } a_{12 \text { (res. }} a_{62} \text { ) with } a_{15} a_{65} \text { ) } \\
& \text { interchange } a_{21 \text { (res. }} a_{26 \text { ) with }} a_{51 \text { (res. }} a_{56} \text { ) } \\
& \text { interchange } a_{22}{ }_{\text {(res. }} a_{25} \text { ) with } a_{55 \text { (res. }} a_{52} \text { ) } \\
& \text { interchange } a_{23} \text { (res. } a_{24} \text { ) with } a_{53} \text { (res. } a_{54} \text { ) } \\
& \text { interchange } a_{32} a_{42 \text { (res. }} a_{35 \text { (res. }} a_{45} \text { ) }
\end{aligned}
$$

It is obvious that the center remains unchanged by this transformation. This means that a square with negative (positive) center will be transformed into another one of the same kind. We can use this transformation to reduce the number of computed natural magic squares. In order to eliminate the effect of the previous transformations we compute all natural four corner magic squares for which the following conditions hold:

$$
a<2 s-a-b-e,+a<e<b, p<q(>0)
$$

[3] This means that we compute first the number of all natural squares satisfying these conditions. We multiply then this number by sixteen in order to get the number of squares. [4]

\section{[5] 2.3. The Semi Pandiagonal Magic Squares}

We can generalize the concept of four corner magic square to the semi pandiagonal magic square. It has the following structure:

where

$\mathrm{A}=4 \mathrm{~s}-2 \mathrm{~d}-\mathrm{f}-\mathrm{h}-1-\mathrm{n}-\mathrm{p}-2 \mathrm{q}-2 \mathrm{a}+2 \mathrm{u}+2 \mathrm{v}-\mathrm{x}-\mathrm{y}+2 \mathrm{z}$,

$\mathrm{B}=\mathrm{a}-\mathrm{c}+\mathrm{d}+\mathrm{h}+\mathrm{l}+\mathrm{n}+\mathrm{p}+2 \mathrm{q}-\mathrm{s}-2 \mathrm{u}-2 \mathrm{v}+\mathrm{x}+\mathrm{y}-2 \mathrm{z}$,

$\mathrm{D}=\mathrm{o}-\mathrm{k}-\mathrm{l}-\mathrm{h}+\mathrm{s}+\mathrm{e}, \quad \mathrm{E}=2 \mathrm{~s}-\mathrm{o}-\mathrm{m}-\mathrm{e}, \mathrm{F}=\mathrm{m}-\mathrm{a}+\mathrm{o}-\mathrm{s}$ $+\mathrm{v}+\mathrm{z}$

$\mathrm{G}=2 \mathrm{~s}-\mathrm{u}-\mathrm{v}-\mathrm{z}$

$\mathrm{H}=4 \mathrm{~s}-\mathrm{l}-\mathrm{p}-\mathrm{r}-\mathrm{i}-\mathrm{k}-\mathrm{x}-\mathrm{y}, \quad \mathrm{J}=\mathrm{s}-1-\mathrm{d}+\mathrm{u}-\mathrm{x}+\mathrm{z}$,

$\mathrm{L}=\mathrm{d}-\mathrm{c}+\mathrm{l}+\mathrm{m}+\mathrm{o}+\mathrm{p}+\mathrm{q}-\mathrm{s}-2 \mathrm{u}-\mathrm{v}+\mathrm{x}+\mathrm{y}-\mathrm{z}$,

$\mathrm{M}=\mathrm{c}-\mathrm{a}-\mathrm{d}-\mathrm{h}-\mathrm{l}-\mathrm{m}-\mathrm{n}-\mathrm{o}-\mathrm{p}-2 \mathrm{q}+4 \mathrm{~s}+2 \mathrm{u}+\mathrm{v}-\mathrm{x}-$

$\mathrm{y}+\mathrm{z}$

$\mathrm{N}=3 \mathrm{~s}-\mathrm{k}-\mathrm{i}-\mathrm{c}-\mathrm{u}-\mathrm{z}$,

$\mathrm{Q}=2 \mathrm{a}+2 \mathrm{~d}+\mathrm{f}+\mathrm{h}+\mathrm{l}+\mathrm{m}+\mathrm{n}+2 \mathrm{q}-\mathrm{r}-3 \mathrm{~s}-2 \mathrm{u}-2 \mathrm{v}+\mathrm{x}+\mathrm{y}$

$-2 \mathrm{z}+\mathrm{e}$,

$\mathrm{R}=\mathrm{c}-\mathrm{d}+\mathrm{k}-\mathrm{m}-\mathrm{o}-\mathrm{q}+\mathrm{i}+\mathrm{u}+\mathrm{z}$,
$\mathrm{T}=\mathrm{s}-\mathrm{q}-\mathrm{p}+\mathrm{u}+\mathrm{v}-\mathrm{y}, \quad \mathrm{W}=\mathrm{k}-\mathrm{f}+\mathrm{l}-\mathrm{m}+\mathrm{p}+\mathrm{r}+\mathrm{i}-\mathrm{s}$

$+\mathrm{x}-\mathrm{e}$,

$\mathrm{Y}=3 \mathrm{~s}-\mathrm{o}-\mathrm{I}-\mathrm{n}-\mathrm{x}-\mathrm{e}$.

It is easy to see that each four corner magic is a semi pandiagonal magic square. Further, the transformations considered in 2.3 are property preserving for this new type.

It is worth mentioning that the two dependent variables in the frame of center square $(\mathrm{E}$ and $\mathrm{H})$ depends only on the variables in the outer frame. This is helpful by programming in order to reduce run time. The problem of counting the natural squares of this type of squares is yet unsolved.

\begin{tabular}{|l|l|l|l|l|l|}
\hline 6 & 23 & 11 & 13 & 33 & 25 \\
\hline 19 & 28 & 36 & 3 & 7 & 18 \\
\hline 2 & 29 & 1 & 17 & 27 & 35 \\
\hline 21 & 8 & 22 & 34 & 10 & 16 \\
\hline 32 & 9 & 15 & 20 & 30 & 5 \\
\hline 31 & 14 & 26 & 24 & 4 & 12 \\
\hline
\end{tabular}

\begin{tabular}{|l|l|l|l|l|l|}
\hline $\mathrm{a}$ & $\mathrm{i}$ & $\mathrm{c}$ & $\mathrm{d}$ & $\mathrm{f}$ & $\mathrm{z}$ \\
\hline $\mathrm{h}$ & $\mathrm{o}$ & $\mathrm{o}$ & $\mathrm{o}$ & $\mathrm{o}$ & $\mathrm{s}-\mathrm{h}$ \\
\hline $\mathrm{p}$ & $\mathrm{o}$ & $\mathrm{u}$ & $\mathrm{v}$ & $\mathrm{o}$ & $\mathrm{R}$ \\
\hline $\mathrm{q}$ & $\mathrm{o}$ & $\mathrm{z}$ & $\mathrm{G}$ & $\mathrm{o}$ & $\mathrm{T}$ \\
\hline $\mathrm{n}$ & $\mathrm{o}$ & $\mathrm{o}$ & $\mathrm{o}$ & $\mathrm{o}$ & $\mathrm{s}-\mathrm{n}$ \\
\hline $\mathrm{m}$ & $\mathrm{q}$ & $\mathrm{t}$ & $\mathrm{w}$ & $\mathrm{j}$ & $\mathrm{k}$ \\
\hline
\end{tabular}

[6] 3.0 Symbolic Computations of the Determinant

It is sometimes of interest to determine the determinant of the magic square as a square matrix. In the case of the semi pandiagonal magic squares there are cases when the determinant is zero. In general the determinant is not zero for any semi pandiagonal magic square. In case we have all entries of the frame of outer 4 by 4 center (E, k, 1, m, r, H, p, y, o and e) equal to the value $0.5 s$. Then, we can compute using symbolic calculation software that the determinant is zero. In fact we can verify that any square of the following type has this property:

A symbolic square with zero determinant

\begin{tabular}{|l|l|l|l|l|l|}
\hline a & A & c & d & f & B \\
\hline h & E & k & l & m & D \\
\hline L & r & u & v & H & R \\
\hline q & p & z & G & y & T \\
\hline n & o & i & X & e & Y \\
\hline M & Q & N & W & J & F \\
\hline
\end{tabular}

We used computers to count the several types of four corner magic squares. The used code can be found in [11]. The new results in this paper are the enumeration of four corner magic 
squares having a negative determinant center, which is neither symmetric nor semi symmetric. Moreover, the value of a is 6,7 or 8 . In other words we consider the all centers such that

$\mathrm{a}<\mathrm{e}<\mathrm{b}, \quad 5<\mathrm{a}<9,2 \mathrm{~s}-\mathrm{a}-\mathrm{b}-\mathrm{e}>\mathrm{a}, \quad \mathrm{a}(2 \mathrm{~s}-\mathrm{a}-\mathrm{b}-\mathrm{e})>$ be $(3)$

In the following tables we list the number for squares associated with such centres:

list of the number with $a=6$

\begin{tabular}{|l|l|l|l|l|l|}
\hline $\mathrm{b}$ & Center & number & $\mathrm{b}$ & Center & number \\
\hline $17, \ldots$ & 27 & 346261873 & 29 & 20 & 272033548 \\
\hline 22,23 & 22 & 287762795 & 30 & 20 & 283550183 \\
\hline 24 & 12 & 161521602 & 32 & 22 & 318578923 \\
\hline 25 & 14 & 183266068 & 33 & 22 & 317504330 \\
\hline 26 & 15 & 194563395 & 34 & 20 & 305173556 \\
\hline 27 & 17 & 226208507 & 35 & 20 & 298075640 \\
\hline 28 & 17 & 230224612 & 36 & 18 & 277953702 \\
\hline
\end{tabular}

The total number of centers associated with $\mathrm{a}=6$ is 266 . The total number of the squares is

37026787410 .

list of the number with $\mathrm{a}=7$

\begin{tabular}{|l|l|l|l|l|l|}
\hline $\mathrm{b}$ & Center & number & $\mathrm{b}$ & Center & Number \\
\hline $17, \ldots$ & 25 & 316631539 & 29 & 18 & 247062408 \\
\hline 22,23 & 19 & 243590512 & 31 & 20 & 283550183 \\
\hline 24 & 12 & 154169309 & 32 & 20 & 278823415 \\
\hline 25 & 12 & 155140031 & 33 & 18 & 259302122 \\
\hline 26 & 15 & 196132602 & 34 & 18 & 260058312 \\
\hline 27 & 15 & 197439548 & 35 & 16 & 238403631 \\
\hline 28 & 18 & 245964322 & 36 & 16 & 237122233 \\
\hline
\end{tabular}

The total number of centers associated with $\mathrm{a}=7$ is 242 . The total number of the squares is

33133901727.

list of the number with $\mathrm{a}=8$

\begin{tabular}{|l|l|l|l|l|l|}
\hline $\mathrm{b}$ & Center & number & $\mathrm{b}$ & Center & number \\
\hline $17, \ldots$ & 20 & 246525148 & 30 & 18 & 247062408 \\
\hline 22 & 9 & 111325270 & 31 & 18 & 242346384 \\
\hline 23 & 9 & 112204862 & 32 & 16 & 226856629 \\
\hline 24 & 10 & 125123289 & 33 & 16 & 226690971 \\
\hline 25 & 13 & 165470930 & 34 & 14 & 199026621 \\
\hline 26 & 13 & 169068613 & 35 & 14 & 205014664 \\
\hline 27 & 16 & 214393636 & 36 & 12 & 175733360 \\
\hline 28 & 16 & 213891504 & $*$ & $*$ & $*$ \\
\hline
\end{tabular}

The total number of centers associated with $a=8$ is 214 . The total number of the squares is
27807342954.

[7] As summary, we have 2738 centers, which are neither symmetric nor semi symmetric and have negative determinant. Based on the data in [6], [7] and in this paper we state: the number of the squares associated with these centers is represented in the following list:

List of the number with $\mathrm{a}=1, \ldots, 16$

\begin{tabular}{|l|l|l|l|l|l|}
\hline a & Center & number & a & Center & number \\
\hline 1 & 255 & 3852302267 & 9 & 183 & 2412601781 \\
\hline 2 & 270 & 4066291938 & 10 & 152 & 1762923729 \\
\hline 3 & 279 & 3962819394 & 11 & 121 & 1524419994 \\
\hline 4 & 282 & 4086636847 & 12 & 87 & 1106188872 \\
\hline 5 & 280 & 3966691562 & 13 & 55 & 7037768734 \\
\hline 6 & 266 & 3715782866 & 14 & 33 & 4328085633 \\
\hline 7 & 242 & 3313390172 & 15 & 15 & 2059934349 \\
\hline 8 & 214 & 2780734295 & 16 & 4 & 618706214 \\
\hline
\end{tabular}

When we sum all numbers together we conclude that: the number of the squares with negative center is 379552332175 .

Hence, the total number of the squares with negative center is $379552332175 * 16=6072837314$

There are 232 centers of the natural positive determinant four corner magic squares. According to [9] there are

$30350772825 * 16=485612365200$

squares of this type. There are 153 possible symmetric centers of the natural four corner magic squares. According to [11] there are

$28634584244 * 16=458153347904$

different natural four corner magic squares with symmetric center. There are 306 possible semi symmetric centers of the natural four corner magic squares. According to [10] there are $101425060998 * 16=1622800975968$

different natural four corner magic squares with semi symmetric center. Hence, there are

\section{2}

different four corner magic squares of order six.

The problem of counting the number of squares of order six has been now completely solved. We see that the maximum number of squares for a fixed center is the number generated by the semi symmetric center

$\mathrm{a}=17, \mathrm{~b}=20, \mathrm{e}=18$

It is 398369256 . Further, the minimum number of squares for a fixed center is the number generated by the symmetric center

$\mathrm{a}=1, \mathrm{~b}=35, \mathrm{e}=2$.

It is 80012582 .

\section{GENERAL BALANCED MAGIC SQUARE}

4.1 The case of any order

We distinguish between even and odd order for a magic square in the definition. A $2 l$ by $2 l$ magic square is called balanced iff

$a_{k, k}+a_{k, 2 l+1-k}+a_{2 l+1-k, k}+a_{2 l+1-k, 2 l+1-k}=2 s$, for all $1 \leq k \leq l$, 
where $s=(2 l)^{2}+1$. This means the four corners of the center squares sum up to $2 s$ each.

In case of $2 l+1$ by $2 l+1$ magic square then we require that

$a_{k, k}+a_{k, 2(l+1)-k}+a_{2(l+1)-k, k}+a_{2(l+1)-k, 2(l+1)-k}=4 s$, for all $1 \leq k$ $\leq l$,

$a_{l+1, l+1}=s, \quad s=2 l^{2}+2 l+1$.

It is well-known that the following structure

\begin{tabular}{|c|c|c|c|}
\hline $\mathrm{h}$ & $\mathrm{i}$ & $\mathrm{j}$ & $2 \mathrm{~s}-\mathrm{h}-\mathrm{i}-\mathrm{j}$ \\
\hline $\mathrm{v}$ & $q$ & $\begin{array}{l}2 s-v-q- \\
1\end{array}$ & 1 \\
\hline $\begin{array}{l}6 s \\
-(1+g+i+j)-2(q+h+v \\
)\end{array}$ & $\begin{array}{l}2 s \\
- \\
g \\
- \\
q\end{array}$ & $\begin{array}{l}1+v+g+q-2 \\
s\end{array}$ & $2(h+q)+i+j+v+g-4 s$ \\
\hline $\begin{array}{l}1+v+g+h+i+j+2 q- \\
4 s\end{array}$ & $\begin{array}{l}\mathrm{g} \\
- \\
\mathrm{i}\end{array}$ & $2 s-g-j$ & $4 s-h-2 q-1-v-g$ \\
\hline
\end{tabular}

\begin{tabular}{|l|l|l|l|l|}
\hline a & j & C & D & f \\
\hline h & n & K & l & m \\
\hline b & r & u & v & t \\
\hline q & p & z & $2 s-u-v-z$ & y \\
\hline g & o & i & x & 2s $-\mathrm{n}-\mathrm{o}-\mathrm{m}$ \\
\hline T & Y & R & E & G \\
\hline
\end{tabular}

is a general structure of the magic square 4 by 4 . Here, the magic constant is $2 \mathrm{~s}$. So, we can say that all magic square 4 by 4 are balanced. Also, all natural magic square 3 by 3 are balanced, while there are according to our calculations just $830396 \cdot 4 \cdot 8=26572672$

balanced natural magic square 5 by 5 . The number of balanced natural magic square of orders 6 and higher is still open.

Actually, it is well-known that the following structure

\begin{tabular}{|l|l|l|l|l|l|l|}
\hline $\mathrm{A}$ & $\mathrm{B}$ & $\mathrm{D}$ & $\mathrm{E}$ & $\mathrm{F}$ & $\mathrm{f}$ & $\mathrm{G}$ \\
\hline $\mathrm{H}$ & $\mathrm{J}$ & $\mathrm{i}$ & $\mathrm{j}$ & $\mathrm{K}$ & $\mathrm{l}$ & $\mathrm{L}$ \\
\hline $\mathrm{m}$ & $\mathrm{n}$ & $\mathrm{o}$ & $\mathrm{p}$ & $\mathrm{q}$ & $\mathrm{r}$ & $\mathrm{R}$ \\
\hline $\mathrm{t}$ & $\mathrm{u}$ & $\mathrm{W}$ & $\mathrm{s}$ & $2 \mathrm{~s}-\mathrm{W}$ & $2 \mathrm{~s}-\mathrm{u}$ & $2 \mathrm{~s}-\mathrm{t}$ \\
\hline $2 \mathrm{~s}-\mathrm{R}$ & $2 \mathrm{~s}-\mathrm{r}$ & $2 \mathrm{~s}-\mathrm{q}$ & $2 \mathrm{~s}-\mathrm{p}$ & $2 \mathrm{~s}-\mathrm{o}$ & $2 \mathrm{~s}-\mathrm{n}$ & $2 \mathrm{~s}-\mathrm{m}$ \\
\hline $2 \mathrm{~s}-\mathrm{L}$ & $2 \mathrm{~s}-\mathrm{l}$ & $\begin{array}{l}2 \mathrm{~s}- \\
\mathrm{K}\end{array}$ & $2 \mathrm{~s}-\mathrm{j}$ & $2 \mathrm{~s}-\mathrm{i}$ & $2 \mathrm{~s}-\mathrm{J}$ & $2 \mathrm{~s}-\mathrm{H}$ \\
\hline $\begin{array}{l}2 \mathrm{~s}- \\
\mathrm{G}\end{array}$ & $2 \mathrm{~s}-\mathrm{f}$ & $2 \mathrm{~s}-\mathrm{F}$ & $2 \mathrm{~s}-\mathrm{E}$ & $2 \mathrm{~s}-\mathrm{D}$ & $2 \mathrm{~s}-\mathrm{B}$ & $2 \mathrm{~s}-\mathrm{A}$ \\
\hline
\end{tabular}

where

$\mathrm{A}=2 \mathrm{i}+6 \mathrm{~s}+1-2 \mathrm{f}-2 \mathrm{r}-4 \mathrm{~m}+\mathrm{t}-\mathrm{o}-\mathrm{p}-\mathrm{u}+2 \mathrm{j}, \mathrm{B}=\mathrm{n}-\mathrm{f}+\mathrm{q}$ $+\mathrm{r}+\mathrm{o}+\mathrm{j}-3 \mathrm{~s}$,

$\mathrm{D}=\mathrm{u}-\mathrm{j}+\mathrm{s}+\mathrm{m}+\mathrm{n}-\mathrm{i}-1, \mathrm{E}=2 \mathrm{f}+6 \mathrm{~s}-2 \mathrm{i}+2 \mathrm{~m}-\mathrm{t}-2 \mathrm{j}-$ $2 \mathrm{n}-\mathrm{q}-\mathrm{o}$,

$\mathrm{F}=3 \mathrm{~s}-\mathrm{l}-\mathrm{i}+\mathrm{r}+\mathrm{m}-\mathrm{t}-\mathrm{j}, \mathrm{G}=2 \mathrm{i}+\mathrm{l}+\mathrm{t}+\mathrm{j}+\mathrm{o}+\mathrm{p}-6 \mathrm{~s}$, $\mathrm{H}=\mathrm{f}+\mathrm{r}+2 \mathrm{~m}+\mathrm{o}+\mathrm{p}+\mathrm{u}-\mathrm{j}-\mathrm{i}-2 \mathrm{~s}-\mathrm{l}-\mathrm{t}, \mathrm{J}=4 \mathrm{~s}+2 \mathrm{f}+1-$ $\mathrm{q}-\mathrm{o}-\mathrm{j}-\mathrm{u}-2 \mathrm{n}$,

$\mathrm{K}=3 \mathrm{~s}+\mathrm{i}-2 \mathrm{f}-\mathrm{r}-2 \mathrm{~m}+\mathrm{t}-\mathrm{p}+\mathrm{j}+\mathrm{n}, \mathrm{L}=2 \mathrm{~s}+\mathrm{n}-1-\mathrm{f}-\mathrm{i}+\mathrm{q}$, $R=7 s-m-n-o-p-q-r, W=6 s+q-o+j-2 f-2 m-p$ $-\mathrm{u}$.

is a general structure of the symmetric pandiagonal magic square 7 by 7 . Here, the magic constant is $7 \mathrm{~s}$. Of course, such magic squares are balanced. The number of natural symmetric pandiagonal magic square is

20190684.

We call a matrix $\left(a_{i j}\right)$ a balanced magic 6x6 square if

$a_{11}+a_{61}+a_{16}+a_{66}=2 \mathrm{~s}$

$a_{22}+a_{25}+a_{52}+a_{55}=2 \mathrm{~s}$

$a_{33}+a_{43}+a_{34}+a_{44}=2 \mathrm{~s}$

Compared with a general magic square we have 3 additional equations (the corner sum of the center $2 \times 2,4 \times 4,6 \times 6$ square),

\begin{tabular}{|l|}
\hline $3 s-a-j-c-D-f$ \\
\hline $3 s-K-l-m-n-h$ \\
\hline $3 s-u-v-x-r-b$ \\
\hline$s-q-p+u+v-y$ \\
\hline$m+n+s-i-x-g$ \\
\hline$m+v+z+o-a-s$ \\
\hline
\end{tabular}

but only 2 are linearly independent in the whole set of equations. Hence, there are 21 independent variables for balanced magic $6 \times 6$ squares.

4.2 The case of order six

We present a general form of balanced magic $6 \times 6$ squares as follows:

where

$\mathrm{D}=3 \mathrm{~s}-2 \mathrm{a}-\mathrm{h}-\mathrm{b}-\mathrm{q}-\mathrm{g}-\mathrm{j}-\mathrm{c}-\mathrm{f}+\mathrm{m}+\mathrm{v}+\mathrm{z}+\mathrm{o}$,

$\mathrm{E}=\mathrm{s}-\mathrm{D}-\mathrm{l}-\mathrm{x}+\mathrm{u}+\mathrm{z}, \mathrm{G}=\mathrm{s}-\mathrm{f}-\mathrm{t}-\mathrm{y}+\mathrm{n}+\mathrm{o}$,

$\mathrm{K}=4 \mathrm{~s}-(\mathrm{l}+\mathrm{p}+\mathrm{r}+\mathrm{t}+\mathrm{x}+\mathrm{y}+\mathrm{i}), \mathrm{T}=3 \mathrm{~s}-\mathrm{a}-\mathrm{h}-\mathrm{b}-\mathrm{q}-\mathrm{g}$, $\mathrm{Y}=3 \mathrm{~s}-\mathrm{j}-\mathrm{n}-\mathrm{o}-\mathrm{p}-\mathrm{r}, \mathrm{R}=3 \mathrm{~s}-\mathrm{c}-\mathrm{K}-\mathrm{i}-\mathrm{u}-\mathrm{z}$.

We notice that it has 21 free variables.

For a semi-pandiagonal magic square we additionally require the following sums for 2 broken diagonals:

$a_{31}+a_{22}+a_{13}+a_{64}+a_{55}+a_{46}=3 \mathrm{~s}$

$a_{41}+a_{52}+a_{63}+a_{14}+a_{25}+a_{36}=3 \mathrm{~s}$

If one of these equations is satisfied in a balanced magic square of order 6 then the other equation is satisfied, too. Therefore we get only one additional free variable. From

$\mathrm{b}+\mathrm{n}+\mathrm{c}+\mathrm{E}+(2 \mathrm{~s}-\mathrm{n}-\mathrm{o}-\mathrm{m})+(\mathrm{s}-\mathrm{q}-\mathrm{p}+\mathrm{u}+\mathrm{v}-\mathrm{y})=3 \mathrm{~s}$

(3)

we obtain

$\mathrm{p}=2(\mathrm{a}+\mathrm{b}+\mathrm{c}+\mathrm{u}-\mathrm{m}-\mathrm{o}-\mathrm{s})+\mathrm{f}+\mathrm{g}+\mathrm{h}+\mathrm{j}-\mathrm{l}-\mathrm{x}-\mathrm{y}$ 
By using this value for $\mathrm{p}$ we obtain a general form for balanced semi-pandiagonal magic squares of order 6 . It has 20 free variables, which coincide with the previous definition.

\subsection{The case of any order seven}

How many natural balanced pandiagonal magic squares 7 by 7 are there? In order to solve this open problem we consider first the general form of such squares:

\begin{tabular}{|l|l|l|l|l|l|l|}
\hline $\mathrm{A}$ & $\mathrm{B}$ & $\mathrm{c}$ & $\mathrm{d}$ & $\mathrm{e}$ & $\mathrm{f}$ & $\eta$ \\
\hline $\mathrm{G}$ & $\mathrm{h}$ & $\mathrm{J}$ & $\mathrm{K}$ & $\mathrm{l}$ & $\mathrm{m}$ & $\sigma$ \\
\hline $\mathrm{n}$ & $\mathrm{o}$ & $\mathrm{p}$ & $\mathrm{q}$ & $\mathrm{R}$ & $\mathrm{i}$ & $\xi$ \\
\hline $\mathrm{u}$ & $\mathrm{v}$ & $\varepsilon$ & $\mathrm{s}$ & $\mathrm{x}$ & $\mathrm{z}$ & $4 \mathrm{~s}-\mathrm{t}-\mathrm{u}-\mathrm{d}$ \\
\hline$\Gamma$ & $\tau$ & $\Sigma$ & $4 \mathrm{~s}-\mathrm{q}-\mathrm{x}-\varepsilon$ & $\begin{array}{l}4 \mathrm{~s}-\mathrm{p}-\mathrm{R} \\
-\Sigma\end{array}$ & $\mathrm{y}$ & $\vartheta$ \\
\hline$\Theta$ & $\delta$ & $\phi$ & $\begin{array}{l}4 \mathrm{~s}-\mathrm{K}-\mathrm{v}- \\
\mathrm{z}\end{array}$ & $\psi$ & $\begin{array}{l}4 \mathrm{~s}-\mathrm{m}-\mathrm{h} \\
-\delta\end{array}$ & $\alpha$ \\
\hline$\lambda$ & $\rho$ & $\Pi$ & $\mathrm{t}$ & $\mathrm{w}$ & $\mu$ & $\begin{array}{l}4 \mathrm{~s}-\mathrm{A}-\lambda- \\
\eta\end{array}$ \\
\hline
\end{tabular}

$\mathrm{A}=\mathrm{f}-\mathrm{d}-\mathrm{j}+\mathrm{m}-\mathrm{O}-\mathrm{p}-\mathrm{u}+\mathrm{y}+\mathrm{z}+\mu-\phi+2 \mathrm{~s}, \mathrm{~B}=\mathrm{u}-\mathrm{f}-\mathrm{h}-\mathrm{n}-\mathrm{q}-\mathrm{c}-\mathrm{y}$ $+\phi+5 s$

$\mathrm{G}=\mathrm{c}+\mathrm{e}+\mathrm{f}+\mathrm{x}+\mathrm{y}+\mathrm{z}-\mathrm{d}-\mathrm{j}+\mathrm{m}-2 \mathrm{o}-\mathrm{p}-\mathrm{u}, \mathrm{K}=\mathrm{o}-\mathrm{h}-\mathrm{m}-\mathrm{c}+$ $\mathrm{i}-\mathrm{t}-\mathrm{e}+4 \mathrm{~s}$

$\mathrm{R}=\mathrm{c}-\mathrm{d}+\mathrm{h}-\mathrm{j}-\mathrm{l}+\mathrm{m}-2 \mathrm{o}-\mathrm{p}-\mathrm{q}-2 \mathrm{i}+\mathrm{t}+\mathrm{e}+5 \mathrm{~s}, \mathrm{w}=\mathrm{i}-\mathrm{d}-\mathrm{t}-\mathrm{u}+\mathrm{y}$ $+\mathrm{z}-\mathrm{e}+2 \mathrm{~s}$,

$\Gamma=\mathrm{d}-\mathrm{f}+\mathrm{j}-\mathrm{n}-\mathrm{i}+\mathrm{t}+\mathrm{u}-\mathrm{v}-\mathrm{y}-\mathrm{z}-\mu+\phi+3 \mathrm{~s}$,

$\Theta=\mathrm{j}-\mathrm{f}-\mathrm{c}-\mathrm{m}+2 \mathrm{o}+\mathrm{p}+\mathrm{i}-\mathrm{t}+\mathrm{v}-\mathrm{e}, \psi=\mathrm{d}+\mathrm{u}-\mathrm{c}-\mathrm{h}-\mathrm{n}-\mathrm{y}+3 \mathrm{~s}$, $\rho=\mathrm{d}+\mathrm{j}+\mathrm{l}+\mathrm{q}-\mathrm{v}-\mathrm{z}-\mu, \tau=\mathrm{c}+\mathrm{h}+\mathrm{n}-\mathrm{d}-\mathrm{j}-\mathrm{l}-\mathrm{o}-\mathrm{i}-\mathrm{u}-\phi+5 \mathrm{~s}$, $\varepsilon=\mathrm{d}+\mathrm{t}-\mathrm{v}-\mathrm{x}-\mathrm{z}+2 \mathrm{~s}, \Sigma=1+\mathrm{x}+\mathrm{z}-\mathrm{h}-\mathrm{c}-\mathrm{n}-\mathrm{p}+\mathrm{i}-\mathrm{t}+2 \mathrm{~s}$,

$\delta=\mathrm{f}+\mathrm{i}+\mathrm{y}+\mathrm{z}+\mu-\mathrm{h}-3 \mathrm{~s}, \eta=\mathrm{h}+\mathrm{j}+\mathrm{n}+\mathrm{o}+\mathrm{p}+$ $\mathrm{q}-\mathrm{f}-\mathrm{m}-\mathrm{z}-\mu-\mathrm{e}$,

$\lambda=\mathrm{d}-\mathrm{m}+\mathrm{o}+\mathrm{p}-\mathrm{x}-\mathrm{y}-\mathrm{z}+2 \mathrm{~s}, \Pi=\mathrm{h}+\mathrm{n}+\mathrm{v}-\mathrm{d}-\mathrm{j}-\mathrm{l}-\mathrm{i}-\phi+3 \mathrm{~s}$,

$\vartheta=\mathrm{f}+\mathrm{e}+\mathrm{m}+\mathrm{t}+\mu-\mathrm{j}-\mathrm{o}-2 \mathrm{~s}, \sigma=7 \mathrm{~s}-\mathrm{G}-\mathrm{h}-\mathrm{j}-\mathrm{K}-\mathrm{l}-\mathrm{m}$,

$\alpha=\mathrm{c}+\mathrm{f}+\mathrm{h}+\mathrm{m}+\mathrm{n}+\mathrm{y}+\mathrm{z}-\mathrm{d}-\mathrm{j}-\mathrm{o}-\mathrm{p}-\mathrm{u}-\phi, \xi$ $=7 \mathrm{~s}-\mathrm{n}-\mathrm{o}-\mathrm{p}-\mathrm{q}-\mathrm{R}-\mathrm{i}$.

It has 21 independent variables. This seems to be a more difficult problem than counting the balanced squares 6 by 6 . We shall note that we have now a wider range of numbers, namely from 1 to 49 , which requires also more calculations.

We consider a special case of this structure. It has a special 5 by 5 square in the center. The general form of it is

\begin{tabular}{|l|l|l|l|l|l|l|}
\hline c & a & h & g & p & q & $\begin{array}{l}50 \\
\text { L }\end{array}$ \\
\hline v & W & N & I & u & $50-x$ & $\begin{array}{l}50 \\
- \\
\text { v }\end{array}$ \\
\hline e & y & k & D & $75-\mathrm{k}-\mathrm{D}$ & $50-\mathrm{y}$ & $\begin{array}{l}50 \\
- \\
\text { e }\end{array}$ \\
\hline
\end{tabular}

\begin{tabular}{|l|l|l|l|l|l|l|}
\hline $\mathrm{b}$ & $\mathrm{z}$ & $\begin{array}{l}100-( \\
2 \mathrm{k}+\mathrm{D})\end{array}$ & 25 & $\begin{array}{l}2 \mathrm{k}+\mathrm{D}-5 \\
0\end{array}$ & $50-\mathrm{z}$ & $\begin{array}{l}50 \\
\mathrm{~b}\end{array}$ \\
\hline $\mathrm{t}$ & $\mathrm{F}$ & $\begin{array}{l}\mathrm{k}+\mathrm{D}-2 \\
5\end{array}$ & $\begin{array}{l}50- \\
\mathrm{D}\end{array}$ & $50-\mathrm{k}$ & $50-\mathrm{F}$ & $\begin{array}{l}50 \\
\mathrm{t}\end{array}$ \\
\hline $\mathrm{m}$ & $\mathrm{x}$ & $50-\mathrm{u}$ & $50-\mathrm{I}$ & $50-\mathrm{N}$ & $50-\mathrm{W}$ & $\begin{array}{l}50 \\
- \\
\mathrm{m}\end{array}$ \\
\hline $\mathrm{L}$ & $\mathrm{s}$ & $\mathrm{j}$ & $50-\mathrm{g}$ & $\mathrm{O}$ & $\mathrm{R}$ & $\begin{array}{l}50 \\
- \\
\mathrm{c}\end{array}$ \\
\hline
\end{tabular}

$a=2 L+v+b-g+j+m-p-q+t-2 u+x-I-W+e-25$

$\mathrm{c}=175-\mathrm{v}-\mathrm{b}-\mathrm{m}-\mathrm{t}-\mathrm{e}-\mathrm{L}$,

$\mathrm{F}=\mathrm{g}-\mathrm{v}-\mathrm{b}-\mathrm{y}-2 \mathrm{~L}-\mathrm{j}-\mathrm{m}+\mathrm{p}+\mathrm{q}-\mathrm{s}-\mathrm{t}+2 \mathrm{u}-2 \mathrm{x}-\mathrm{z}+$ $\mathrm{I}-\mathrm{e}+200$,

$\mathrm{h}=2 \mathrm{u}-\mathrm{j}-\mathrm{x}+\mathrm{I}+\mathrm{W}-25, \quad \mathrm{~N}=\mathrm{x}-\mathrm{u}-\mathrm{I}-\mathrm{W}+75$, $\mathrm{O}=\mathrm{x}-2 \mathrm{u}-\mathrm{p}-\mathrm{I}-\mathrm{W}+125, \quad \mathrm{R}=\mathrm{g}-\mathrm{v}-\mathrm{b}-2 \mathrm{~L}-\mathrm{j}-\mathrm{m}+\mathrm{p}$ $-\mathrm{s}-\mathrm{t}+2 \mathrm{u}-\mathrm{x}+\mathrm{I}+\mathrm{W}-\mathrm{e}+125$.

It has 18 independent variables. We see that the center is a 3 by 3 magic square. The center is independent of the other cells. We fix the center and then count the squares such that $\mathrm{W}<\mathrm{x}<50-\mathrm{x}, \mathrm{W}<50-\mathrm{W}$.

We restate this condition as $\mathrm{W}<\mathrm{x}<25$.

\section{CONCLUSION}

\subsection{Conclusion}

We have considered many types of magic squares. We talked about the way how to calculate their number. Sometimes we had to consider subsets of the general class in order to be able to calculate the number in reasonable time.

\subsection{Suggestion}

We may try to find more property preserving transformations. This will help by reducing the run time. We shall also try to write the codes for the computations by using nested loops in such way, which allows parallel computing. By doing this we can reduce the time of calculations. Also, the way of checking the conditions of the square can be written in a the manner of backtracking, which reduces the time of calculations.

\section{REFERENCES}

1. Rosser, B. and Walker, J. 1938. On the transformation group for diabolic magic squares of order four. The American Mathematical Society Bulletin. XLIV: 56-73.

2. Bellew J. 1997. Counting the number of compound and nasik magic squares. Mathematics Today: 111-118.

3. Grogono Magic Squares Home Page, accessed 28 November 2019. https://www.grogono.com/magic/ 
4. Ollerenshaw, K. and Brée, D. S. 1998. Most-perfect pandiagonal magic squares: their construction and enumeration. The Institute of Mathematics And its Applications. U.K.

5. Al-Ashhab, S. Sh. 2008. Magic squares 5x5. The international journal of applied science and computations. 1(15): 53-64.

6. Al-Ashhab, S. Sh. 2015. The number of four corner magic squares of order six. British Journal of Applied Science \& Technology 7(2). 132: 141-155. https://doi.org/10.9734/BJAST/2015/13383

7. Al-Ashhab, S. Sh. 2013. Special magic squares of order six. Research Open Journal of Information Science and Application. 1(1): 1-19.

8. Al-Ashhab, S. Sh. 2014. Negative four corner magic squares of order six with a between 1 and 5. Qatar Foundation Annual Research Conference (ARC 2014 conference).

https://doi.org/10.5339/qfarc.2014.ITPP0393

9. Al-Ashhab, S. Sh. 2012. Special magic squares of order six and eight. International Journal of Digital Information and Wireless Communications (IJDIWC). 1(4): 769-781

10. Al-Ashhab, S. Sh. 2012. Even-order magic Squares with special properties. International Journal of Open Problems in Mathematics and Computer Science. 5(2). 167-175. https://doi.org/10.12816/0006103

11. Ahmed, M. 2004. How many squares are there, Mr. Franklin? Constructing and enumerating Franklin squares. American Mathematical Monthly. 111: 394-410. https://doi.org/10.1080/00029890.2004.11920091

12. Abualigah, L. M., Khader, A. T., \& Hanandeh, E. S. (2019). Modified Krill Herd Algorithm for Global Numerical Optimization Problems. In Advances in Nature-Inspired Computing and Applications (pp. 205-221). Springer, Cham.

https://doi.org/10.1007/978-3-319-96451-5_9 